\title{
Alonso de Cartagena y la defensa de la exención del obispado burgalés frente al primado toledano
}

\author{
Alonso de Cartagena and the Defense of the Exemptions of the Bishopric \\ of Burgos with respect to the Primacy of Toledo
}

\author{
Jorge DíAZ IBÁÑEZ \\ Universidad Complutense. Madrid \\ jdiazib@ghis.ucm.es
}

\begin{abstract}
RESUMEN
Defensa que Alonso de Cartagena, obispo de Burgos, hizo del privilegio de exención y directa dependencia respecto a la Santa Sede de que gozaba la diócesis burgalesa, frente a la pretensión del arzobispo de Toledo, Alonso Carrillo de Acuña, de extender sus derechos de primacía a la diócesis de Burgos y desplazarse en su territorio llevando ante sí la cruz alzada como símbolo de su autoridad. Estudio del conflicto que se desarrolló entre los años 1448 y 1453, con intercambio de sanciones espirituales entre ambos prelados, y de la mediación regia y pontificia en la disputa, que terminó con un acuerdo en junio de 1453, en el que se determinó que el arzobispo de Toledo, en su condición de "primado de Hispania" y no como metropolitano, pudiese llevar la cruz alzada ante sí en la ciudad y obispado de Burgos, aunque el prelado toledano hubo de reconocer que la diócesis burgalesa era exenta y dependía directamente de la Santa Sede.
\end{abstract}

Palabras clave: Burgos. Toledo. Alonso de Cartagena. Alonso Carrillo de Acuña. Primacía eclesiástica. Exención diocesana. Castilla. Siglo xv

\begin{abstract}
The bishop of Burgos Alonso de Cartagena's defence of the privilege of exemption and the direct dependence upon the Holy See that his diocese of Burgos enjoyed with respect to the Archbishop of Toledo Alonso Carrillo de Acuña's attempt to extend his rights of primacy to the diocese of Burgos and displace himself within his territory, carrying the lifted cross before him as a symbol of his authority. A study of the conflict that developed from 1448 through 1453, with an exchange of spiritual sanctions between both prelates and royal and pontifical mediation in the dispute, which finalized with an agreement in June 1453, determining that the archbishop of Toledo, in the condition of "first in Hispania" and not as metropolitan, could have the lifted cross carried before him in the city and bishopric of Burgos, although the Toledan prelate had to recognize that the diocese of Burgos was exempt and depended directly on the Holy See.
\end{abstract}

Keywords: Burgos. Toledo. Alonso of Cartagena. Alonso Carrillo of Acuña. Ecclesiastical primacy. Diocesan exemption. Castile. 15th century

Sumario: 1. Primacía eclesiástica y obispados exentos. 2. El pleito entre Alonso de Cartagena y Alonso Carrillo de Acuña, arzobispo de Toledo. Apéndice documental 


\section{PRIMACÍA ECLESIÁSTICA Y OBISPADOS EXENTOS}

La institución de la primacía eclesiástica, ya existente en el Occidente cristiano desde la alta Edad Media, era un título sobre todo honorífico otorgado por el papa a determinados prelados metropolitanos para que gozasen de un rango de superioridad en la jerarquía eclesiástica en determinados ámbitos políticos o reinos, situándose así por encima de los demás arzobispos que no tenían este especial privilegio. Por lo general el primado fue el metropolitano cuya sede era la más antigua o de mayor relevancia histórica y eclesiástica en cada reino o conjunto de reinos. La caracterización jurídica de la primacía resulta extremadamente compleja, y por lo general puede decirse que a menudo su importancia, escasa en el fondo desde un punto de vista jurisdiccional, se valoraba por ser sobre todo un título honorífico que simbolizaba la supremacía de un determinado arzobispo respecto a otros. A fines del siglo XI y principios del XII el papado, atendiendo a las solicitudes de ciertos prelados, creó en el Occidente cristiano varias primacías que vinieron a unirse a las ya existentes.

El arzobispo de Toledo tuvo desde 1088, por concesión de Urbano II, el título de primado in totis Hispaniarum regnis, un rango honorífico que le situaba por encima de los demás arzobispos peninsulares y, por supuesto, de todos los obispos. Dicha primacía basó inicialmente sus derechos en una pretendida superioridad jurisdiccional dentro del episcopado hispano, intermedia entre los metropolitanos y la sede apostólica ${ }^{2}$. Por ello los prelados toledanos siempre pusieron un importante empeño en la defensa de dicha primacía y de todos los posibles privilegios derivados de la misma ${ }^{3}$. No obstante, los metropolitanos de Braga, Tarragona y Santiago de Compostela casi siempre manifestaron su total oposición al reconocimiento de dicha primacía toledana, y ello explica que desde fines del siglo XII el papado dejase de imponer a los arzobispos la sumisión y obediencia al primado, quedando así reducida la primacía toledana sobre todo a una dignidad honorífica, que como tal sería confirmada por la santa sede en numerosas ocasiones a lo largo de la baja Edad Media' ${ }^{4}$. De este modo, tras el pontificado de Honorio III (1216-1227), quien en 1218 había con-

${ }^{1}$ El presente trabajo forma parte del Proyecto de Investigación financiado por el Ministerio de Ciencia e Innovación $n^{\circ}$ HAR2010-16762, titulado Prácticas de consenso y de pacto e instrumentos de representación en la cultura política castellana (siglos XIII al XV).

2 GonzÁlvez Ruiz, R., "La primacía de Toledo y su ámbito territorial”, Memoria Ecclesiae, 28 (2006), p. 423.

${ }^{3}$ Un ejemplo de ello lo tenemos en el texto anónimo titulado Pars Lateranii Concilii, en el que se recoge la intervención del arzobispo de Toledo Rodrigo Jiménez de Rada en el IV Concilio de Letrán de 1215, ante Inocencio III y una amplia asamblea de prelados y otros clérigos, intervención con la que quiso ante todo defender la primacía de la iglesia toledana en el contexto hispánico frente a las sedes de Braga y Compostela. Dicha intervención, a modo de sermón, fue leída en al menos media docena de lenguas, encontrándose revestida de una gran cantidad de elementos retóricos y de legitimación histórica de la primacía toledana. Puede verse al respecto el trabajo de Henriet, P., "Political struggle and the legitimation of the toletan primacy: the Pars Lateranii Concilii", en Building legitimacy. Political discourses and forms of legitimation in Medieval Societies (ed. Isabel Alfonso, Hugh Kennedy, Julio Escalona), Leiden-Boston, 2004, pp. 291-318.

${ }^{4}$ Una de las sedes metropolitanas que más se opusieron a la prestación de cualquier tipo de sumisión y obediencia hacia el primado toledano fue la de Braga. Véase al respecto el trabajo de Feige, 
firmado a Toledo su primacía, ésta quedó en un estado de reconocimiento puramente teórico de sus derechos honoríficos pero de indeterminación en la práctica en cuanto a su ejercicio ${ }^{5}$ y ello explica que algunas metrópolis y obispados exentos, como por ejemplo las sedes de Sevilla y Oviedo, llegaran incluso a negar directamente al arzobispo de Toledo su condición de primado de Hispania .

Con todo, la primacía siempre estuvo presente en la memoria colectiva de la iglesia toledana, y durante toda la baja Edad Media se produjeron choques con diferentes metropolitanos y obispados exentos, al pretender los primados de Toledo llevar ante sí la cruz alzada por todo el territorio peninsular como señal honorífica de la pretendida supremacía jerárquica, e incluso jurisdiccional, que la primacía les confería. Dicha cruz alzada era un símbolo peligroso, pues implicaba jurisdicción suprametropolitana. Podía suceder que cuando los primados de Toledo pasaban con la cruz alzada por diócesis ajenas a su provincia eclesiástica contasen con la benevolencia o aquiescencia de los prelados correspondientes, en caso de que sus relaciones fuesen cordiales. Pero esto último no fue lo más frecuente, por lo que los prelados afectados, sintiéndose vulnerados en su jurisdicción, respondieron a menudo con sentencias de excomunión contra el arzobispo y sus acompañantes, e incluso con el entredicho hacia las poblaciones por las que el primado osaba pasar con la cruz alzada. Debido a ello, el único territorio en el que los primados pudieron portar sin problemas la cruz alzada fue la propia provincia eclesiástica de Toledo, y por lo general desde el siglo XVI renunciarían cada vez más a hacerlo fuera de dicha provincia, para así evitar los posibles conflictos que pudieran ocasionarse $e^{7}$. Más adelante me centraré precisamente en el análisis de uno de estos conflictos, el que a mediados del siglo Xv enfrentó al arzobispo de Toledo Alonso Carrillo de Acuña con el obispo de Burgos Alonso de Cartagena.

Situadas en un nivel jerárquico inferior al de la primacía, las simples diócesis de cada reino, en razón de su tipo de dependencia jurisdiccional, podían ser sufragáneas, es decir, sometidas a la jurisdicción de un determinado metropoliano y englobadas dentro de la provincia eclesiástica que éste presidía, o bien exentas respecto a

P., "La primacía de Toledo y la libertad de las demás metrópolis de España. El ejemplo de Braga", en VV.AA, La introducción del Císter en España y Portugal, Burgos, 1991, pp. 61-132.

5 GonzÁlvez Ruiz, R., "La primacía de Toledo...”, p. 434.

${ }^{6}$ Para el caso de la mitra ovetense, que gozaba del privilegio de exención, ello queda patente en un acuerdo establecido el 20 de abril de 1235 entre su obispo don Juan y el cabildo catedralicio, a través del cual manifiestan conjuntamente no reconocer al arzobispo toledano la condición de primado de Hispania. García Larragueta, S., Catálogo de los pergaminos de la catedral de Oviedo, Oviedo, 1957, p. $114, \mathrm{n}^{\circ} 306$. En cuanto a la metrópoli hispalense, poco tiempo después de ser restaurada sus arzobispos don Remondo (1259-1286) y don García (1289-1294) manifestaron incesantes esfuerzos en defensa de sus antiguos derechos de primacía frente a las sedes de Toledo y Santiago de Compostela, negándose a que los arzobispos de estas últimas entrasen con la cruz primacial alzada en territorios pertenecientes a la jurisdicción eclesiástica hispalense. Cuando esto último sucedió, se establecieron acuerdos que sólo sirvieron para solucionar cada conflicto coyuntural, sublimado en el "gesto" de la cruz alzada, pues cada una de las partes continuó considerando intactos sus pretendidos derechos de primacía, apoyándose para ello en remotos antecedentes históricos. Véanse sobre el particular el análisis y los documentos que aparecen recogidos en el trabajo de Fernández Gómez, M., "La defensa de la primacía de la iglesia de Sevilla en el siglo XIII", Archivo Hispalense, 73 (1990), pp. 35-55.

7 Gonzálvez Ruiz, R., "La primacía de Toledo...”, p. 437. 
cualquier arzobispo y dependientes directamente de la jurisdicción de la santa sede. Esta sumisión al papa se consideraba una auténtica libertad, la libertas sancti Petri, y ello llevaba implícito también la exención de cualquier clase de sumisión a una autoridad que no fuese la pontificia. Por tanto dicha exención también debía serlo frente al primado . En época de Alfonso VI las cuatro sedes hispánicas que obtuvieron la exención fueron las de Compostela, Oviedo, León y Burgos?.

Al obispado de Burgos la exención le fue concedida por Urbano II el 15 de julio de 1096, en época del obispo don Gómez ${ }^{10}$. Burgos era una diócesis de nueva fundación por traslado a ella de una antigua sede cercana. En 1068, siendo rey Sancho II, se había restaurado y dotado la antigua diócesis visigoda de Oca, y en 1075 Alfonso VI determinó el traslado desde Oca a la nueva sede de Burgos, traslado que se haría efectivo en diciembre de $1081^{11}$. Como culminación de este proceso, en 1096 Burgos obtuvo el mencionado privilegio de exención, pasando a depender directamente de la santa sede. Son varias las razones que había para que Urbano II concediese a la diócesis burgalesa este privilegio. Por un lado, la diócesis de Oca, antecesora de Burgos, no había dependido en época visigoda de la metrópoli toledana, sino de la tarraconense. Por otro, al encontrarse Burgos en Castilla, no era conveniente incorporar la sede burgalesa a la provincia tarraconense, pues el monarca castellano se opondría a que Burgos quedara sometida a la jurisdicción de un metropolitano ajeno por completo al reino de Castilla ${ }^{12}$. De este modo, al gozar Burgos de la exención de dependencia hacia cualquier metropolitano, se libraba de las ambiciones del arzobispo de Toledo don Bernardo, que había intentado hacerla depender de su metrópoli alegando que parte del territorio burgalés había pertenecido en época visigoda a la provincia cartaginense ${ }^{13}$. La protección que la santa sede prestó a la diócesis de Burgos frente al arzobispo de Toledo llegó al extremo de excluirla del ámbito de

${ }^{8}$ Ibídem, p. 427.

${ }^{9}$ Sobre los obispados exentos en los reinos hispánicos pueden verse los estudios de Mansilla ReOYo, D., "Obispados exentos de la Iglesia española”, Hispania Sacra, 32 (1980), pp. 287-321, y GAMBrA Gutiérrez, A., "Alfonso VI y la exención de las diócesis de Compostela, Burgos, León y Oviedo", en Estudios sobre Alfonso VI y la Reconquista de Toledo (Actas del II Congreso Internacional de Estudios Mozárabes, Toledo, 20-26 de mayo de 1985), Toledo, 1988, pp. 181-217.

${ }^{10}$ El documento de otorgamiento de esta exención aparece recogido en GARRIDO GARRIDO, J.M., Documentación de la catedral de Burgos (804-1222), Burgos, 1983, vol. 1, doc. nº 61.

${ }^{11}$ Martínez Díez, G., "La Iglesia de Burgos", caps. I-IV de Iglesias de Burgos, Osma-Soria y Santander (vol. 20 de Historia de las diócesis españolas, B.A.C., coord. Bartolomé Martínez, B.), Madrid, 2004, pp. 30-31.

${ }^{12}$ A la posición adoptada por Alfonso VI alude explícitamente la bula de Urbano II (15-VII-1096) en la que se concede a Burgos el privilegio de exención: “...Ceterum Ildefonsus, Hispanie citerioris rex, Burgensem episcopum Tarraconensi metropolitano nequaquam patiebatur esse subiectum, ea de causa, quod infra regni sui terminos Burgus sit, Tarracon autem in Barchinonensis comitis potestate". Se trata de la única ocasión en que aparece explícitamente documentada la intervención de Alfonso VI en la concesión pontificia del privilegio de exención a una diócesis de su reino, que sólo por extensión cabría inferir que también se produjo en otras concesiones similares. Gambra GutiérRez, A., "Alfonso VI y la exención de las diócesis de Compostela, Burgos, León y Oviedo”, p. 210.

${ }_{13}$ Mansilla Reoyo, D., “Obispados exentos de la Iglesia española”, pp. 289-291. La fórmula de obispado exento, aplicada por primera vez a Santiago de Compostela en 1095, se va a repetir en años 
jurisdicción que éste tenía en calidad de legado pontificio, tal como hizo Pascual II en $1104^{14}$. De este modo los obispos de Burgos quedaban libres de sujeción hacia los arzobispos toledanos o cualquier otro metropolitano, gozando de esta exención hasta que el 22 de octubre de 1574 la sede de Burgos fue elevada al rango de arzobispado por decisión del papa Gregorio XIII' ${ }^{15}$.

En función del privilegio de exención de que gozaba su diócesis, los obispos burgaleses legislaron en numerosas ocasiones sobre la prohibición de que cualquier arzobispo, incluido el primado toledano, llevase la cruz alzada como símbolo de su autoridad metropolitana dentro del obispado de Burgos, estableciendo la pena de excomunión para todos aquellos arzobispos que osaran incumplir esta norma, salvo en el caso de que previamente el obispo y cabildo catedralicio de Burgos hubiesen concedido graciosamente a algún arzobispo su autorización para portar la cruz alzada en el territorio del obispado. Dado que el paso de cualquier metropolitano con la cruz alzada por una diócesis constituía un acto simbólico de representación pública de la supremacía de su potestad jurisdiccional sobre dicha diócesis, es lógico que los obispos de Burgos, como titulares de una diócesis exenta, se negaran a aceptar dicha actitud en un arzobispo.

El 30 de diciembre de 1296, por ejemplo, se recogió por escrito el testimonio del paso camino de Roma del arzobispo de Toledo, don Gonzalo, por el obispado de Burgos, públicamente y sin cruz alzada ni símbolo alguno de su potestad ${ }^{16}$. Más de medio siglo después, el 2 de mayo de 1359, el obispo de Burgos Juan Sánchez de Roelas confirmó una constitución anterior según la cual incurrían en excomunión los arzobispos de Santiago, Sevilla y Toledo, y cualquier otro arzobispo, si pasaban por el obispado de Burgos con la cruz alzada ${ }^{17}$. Sin embargo al año siguiente, el 6 de diciembre de 1360, el arzobispo toledano don Gómez reconoció haber recibido del cabildo catedralicio burgalés, estando la sede vacante, "graçia e liçençia para que podamos entrar en la çibdat de Burgos fasta nuestra posada levando la crus alçada", aunque asumiendo que "después que fueremos en nuestra posada que non levemos la dicha crus

sucesivos en diversos obispados hispánicos, muchas veces como único remedio para poner fin a un pleito o cortar ambiciones encontradas de metropolitanos rivales.

${ }^{14}$ Garrido Garrido, J. M., Documentación de la catedral de Burgos..., vol. 1, doc. $\mathrm{n}^{\mathrm{o}} 78$.

${ }^{15}$ Mansilla Reoyo, D., "Obispados exentos de la Iglesia española”, p. 291.

16 “...este día don Gonzalo, por la graçia de Dios arçobispo de Toledo, que posava en Burgos, a varrio de Sant Pedro, ante la puerta de la eglesia, salió de camino de la dicha çibdat por la puente que dizen de los Malatos; e, acompañándoles el onrrado padre e señor don fray Ferrando, por la graçia de Dios obispo de Burgos, con muchos ommes buenos, personas e canónigos e benefiçiados e otros ommes onrrados vezinos de Burgos e de otros lugares, tomó camino el arçobispo sobredicho con su compaña mucha que levava...E salliendo asy de Burgos públicamente, e yendo por el camino, segund dicho es, para la corte de Roma, commo dizen, salió e fue asy todavía el dicho arçobispo syn cruz alçada descubierta e syn otra señal nyn demostramiento ninguno de arçobispo, mas simplemientre commo obispo suele andar...E el obispo e los de la eglesia de Burgos, que yvan y diziendo que esto era en guarda de su eglesia, mandaron a mí, Iohan Pérez, dicho escrivano, que les fiziese ende carta pública, que fue fecha el día e el mes e la era segund dicho es de suso". Archivo Catedralicio de Burgos (en adelante: ACB), vol. 63, f. 248r. Publicado por Pereda Llarena, F. J., Documentación de la catedral de Burgos (12941316), Burgos, 1984, doc. $\mathrm{n}^{\circ} 318$.

${ }_{17}$ ACB, vol. 56, f. 913. 
ante vos por la dicha çibdat nin por el dicho obispado"18. Algunos años más tarde, el 20 de octubre de 1377, el obispo de Burgos don Domingo proclamó la excomunión en la que en esta ocasión había incurrido el arzobispo de Santiago don Rodrigo al haber pasado por la diócesis burgalesa portando la cruz alzada ${ }^{19}$, respecto a lo cual tres días más tarde el metropolitano compostelano declaró, ante el rey Enrique II, que lo había hecho por simple ignorancia y no con la intención de mostrar su supremacía jurisdiccional, reconociendo en todo caso la exención de que gozaba el obispado de Burgos $^{20}$.

\section{EL PLEITO ENTRE ALONSO DE CARTAGENA Y ALONSO CARRILLO DE ACUÑA, ARZOBISPO DE TOLEDO}

Pero desde luego el conflicto más grave que se produjo respecto a esta exención es el que tuvo lugar a mediados del siglo siguiente, en época del obispo Alonso de Cartagena, quien mantuvo un largo pleito al respecto con el arzobispo de Toledo Alonso Carrillo, pleito del que se ha conservado un importante volumen documental ${ }^{21}$. La pretensión del prelado toledano de llevar la cruz alzada en señal de primacía sobre el territorio burgalés en la visita que hizo en el verano de 1448 dio lugar a un enconado y largo conflicto en el que tuvieron que intervenir el papa y el propio rey castellano.

A mediados de agosto de dicho año, encontrándose el rey Juan II en Navarrete camino de Burgos ${ }^{22}$, donde había mandado reunir a los procuradores, el arzobispo Alonso Carrillo, que acompañaba y precedía al monarca en su marcha hacia Burgos, provocó el conflicto al entrar en la ciudad con la cruz alzada en señal de primacía. Cuando esto sucedió, el obispo Alonso de Cartagena y el cabildo catedralicio le pidieron que la retirase inmediatamente, pues no había solicitado licencia para poder hacerlo, dado el privilegio de exención de que gozaba Burgos ${ }^{23}$. Al negarse a ello el prelado toledano, Alonso de Cartagena declaró un entredicho sobre la ciudad de Burgos, ante lo cual el arzobispo reaccionó inmediatamente. Por un lado planteó el problema a uno de los subejecutores de la bula de confirmación de su primacía concedida por Martín V a los arzobispos de Toledo ${ }^{24}$, el prior de la catedral de Córdoba,

${ }^{18}$ ACB, vol. 63 , f. $248 \mathrm{v}$.

19 ACB, vol. 56, f. 912r.

${ }^{20}$ ACB, vol. 7, parte $1^{\text {a }}$, f. 417.

${ }^{21}$ ACB, fundamentalmente vol. 36, ff. 56-132, y en menor medida vols. 7 (parte $1^{\text {a }}$ ) y 56.

${ }^{22}$ El 16 de agosto ya está documentada la estancia de Juan II y la corte en Navarrete, siendo el 12 de septiembre cuando el monarca hizo su entrada en la ciudad de Burgos. Cáñas Gálvez, F. de P., El itinerario de la corte de Juan II de Castilla (1418-1454), Madrid, 2007, p. 431.

23 "que lo non fesiese syn liçençia del dicho señor obispo, la qual él le daría sy la quesiese resçebir... e él respondió que non quería tomar la dicha liçençia nin quería guardar la dicha constituçión, mas que quería entrar commo entró con la dicha cruz enfiesta en la dicha çibdat, por lo qual ovieron lugar las penas en la dicha constituçión contenidas". ACB, vol. 56, ff. 916r-918v.

${ }^{24}$ El reconocimiento y confirmación por parte de Martín V de la primacía a los arzobispos de Toledo había tenido lugar en 1428, quedando ello recogido en varios documentos expedidos durante ese año y el siguiente. En esta confirmación Martín V otorgó al primado las prerrogativas de patriarca, manifestando que ambos cargos se diferenciaban sólo en el nombre. Pero en cambio no se recogieron las necesarias disposiciones tocantes al tipo de jurisdicción que como primado debía tener, lo que sin duda contribuyó a originar los diversos conflictos que se produjeron por la resistencia de algunos prelados 
quien el 19 de agosto procedió a ordenar a todas las autoridades eclesiásticas y civiles de Burgos que acatasen la preeminencia del prelado toledano y se le respetasen todas las prerrogativas que su cargo le daban, exigiendo además que se levantase el entredicho que se había impuesto sobre la ciudad ${ }^{25}$.

Además, Alonso Carrillo acudió a Navarrete junto al monarca en busca de una solución al conflicto que salvaguardase su primacía. El arzobispo narró lo sucedido ante el Consejo y presentó las bulas de Martín V confirmando su primacía. El 20 de agosto el rey, sin moverse de Navarrete, escribió al prelado burgalés, que también era un estrecho colaborador regio, ordenándole que alzase el entredicho y que respetase el honor y preeminencia de que gozaba el primado toledano en función de las mencionadas bulas. En la misma fecha, Juan II escribió otra carta al concejo, alcaldes y demás autoridades civiles de Burgos prohibiéndoles entrometerse en el conflicto que se estaba desarrollando, y mandándoles que permitiesen entrar al arzobispo libremente en la ciudad ${ }^{26}$.

A pesar del mandato regio, tres días más tarde, el 23 de agosto, el obispo Alonso de Cartagena, mediante su procurador Pedro Rodríguez de Grijera, presentaría sus alegaciones y apelación en relación con el proceso apostólico que tiempo atrás se había iniciado ante el ya fallecido Pedro, obispo de Elatea, quien había sido ejecutor de las mencionadas bulas de Martín V a favor de los arzobispos de Toledo, en las que se concedía a éstos, en razón de la primacía de que gozaban, "honor en los asentamientos e en otras cosas, e puedan gosar de çiertas insignias e otras prerrogativas, segund que más largamente en las dichas letras se dise ser contenido" ${ }^{2}$.

Estas alegaciones, un total de doce, iban dirigidas contra los privilegios contenidos en dichas bulas y contra una carta que en relación con todo el asunto había sido emitida por Pedro Fernández Carrillo, prior de Córdoba y juez subejecutor del proceso. En ellas el prelado burgalés, basándose fundamentalmente en argumentos históricos y jurídicos, defendía su opinión de que la condición de primado del arzobispo de Toledo, incluso aunque éste se titulase "primado de las Españas", no debía extenderse a la diócesis de Burgos por encontrarse ésta única y exclusivamente sujeta a la dependencia respecto a la santa sede, por lo cual el arzobispo de Toledo no tenía derecho al empleo en el obispado de Burgos de las insignias y especiales prerrogativas recogidas en las bulas de Martín V:

...E pues la dióçesis de Burgos non es inclusa so términos de primaçía nin patriarcado, salvo solamente so el pontificado romano a quien los obispos de Burgos son inmeditamente subjectos e cuyos son espeçiales sufragáneos, caso que el dicho señor arçobispo sea primado e deva gosar de las insignias de los otros primados, esto sería en otras partes donde se extendiese su primaçía, mas no en esta diócesis, la qual non

castellanos y aragoneses a la ostentación en su diócesis de dicha primacía por parte de los arzobispos de Toledo. Villarroel González, Ó., Las relaciones entre la monarquía y el arzobispado de Toledo en época de Juan II de Castilla (1406-1454), Toledo, 2002, pp. 203-204.

${ }^{25}$ Ibídem, p. 206.

${ }^{26}$ Ibídem, p. 206.

${ }^{27} \mathrm{ACB}$, vol. 36, ff. 58r-62r. El documento completo recogiendo dichas alegaciones aparece transcrito en el apéndice final del presente trabajo. 
es dentro de fines de algund patriarcado nin primaçía, mas sola e inmediatamente so el pontificado romano, nin a esto embarga que digan que sea llamado primado de las Españas, ca nin por eso non se sigue que todas las partes de España sean so su primaçía, ca manifiesta cosa es, asy en derecho commo por experiençia e enxiemplo de otras regiones, que las intitulaçiones generales de las tierras non fasen prueva en cada parte dellas. Por ende, aunque él sea primado de las Españas, non se sigue que todas las partes de España sean so aquella primaçía, e muéstrase esto bien por expiriençia en otras dignidades asy eclegiásticas commo seglares por densas partes del mundo, ca el rey don Alfonso, aquel que ganó a Toledo, que fue en fundar la silla obispal en este obispado e la doctó primeramente, segund por sus escripturas paresçe intitula a la silla obispal desta çibdat por cabeça de la diócesis de toda Castilla, queriendo aver al obispo de Burgos por obispo de toda Castilla, mas non se sigue por eso que toda Castilla es en la diócesis de Burgos, mas porque se pone nombre general a las veses por respecto a la parte más prinçipal, e commo entonçe eran más angostos los términos del reyno llamó a la diócesis de Burgos de toda Castilla... ${ }^{28}$

Por otro lado, en dichas alegaciones, entre otras cuestiones, no se reconocía como juez apostólico en todo el proceso al mencionado Pedro Fernández Carrillo, negándosele cualquier tipo de jurisdicción sobre el asunto. Además, también se alegaban múltiples defectos jurídicos de forma en el modo como se había llevado el proceso, incluido el incumplimiento de determinados plazos de apelación, se acusaba a Pedro Fernández Carrillo de parcialidad por ser familiar del arzobispo de Toledo, se insistía reiteradamente en que los derechos generales de primacía de este último no afectaban en modo alguno a la diócesis de Burgos en particular, por depender ésta exclusivamente de la santa sede, y no de ningún arzobispo ni primado, y finalmente, por todo ello, se apelaba en el pleito ante el papa Nicolás V.

Poco después de presentar estas alegaciones, el 27 de agosto, Alonso de Cartagena lanzó contra el procurador del arzobispo una sentencia de excomunión mayor, fundamentada en las constituciones de sus antecesores en las que se condenaba a dicha pena a todo arzobispo que, salvo licencia expresa al respecto del obispo de Burgos, entrase en la diócesis llevando la cruz alzada, pues ello atentaba gravemente contra la exención e inmunidad de que gozaba el obispado burgalés:

nos ha ofendido e quiere quanto en sy es ofender e quebrantar e menguar la libertad e inmunidat nuestra e de nuestra dignidat obispal e inmediata subjeçión que sobre nos tiene la Santa Sede apostólica, e tumbar la paçífica posesión que de todo ello nuestros predeçesores tovieron e nos tenemos desde tresientos e çinquenta años acá poco más o menos que la silla e dignidat obispal en esta çibdat fue fundada ${ }^{29}$.

${ }^{28}$ ACB, vol. 36, f. 60v.

${ }^{29}$ La sentencia de excomunión se dio contra Pedro Fernández Carrillo, procurador del arzobispo Alonso Carrillo. ACB, vol. 36, ff. 126r-127r. Poco antes dicho Pedro Fernández, en nombre del arzobispo, había publicado cierta carta en contra de la jurisdicción e inmunidad de la diócesis burgalesa. Alonso de Cartagena decretó contra él "canónicamente sentençia de excomunión mayor en estos escriptos e por ellos", mandando a los vicarios generales del obispado publicar dicha sentencia y las cartas citatorias. Ibídem. 
Estando las cosas así, el 12 de septiembre el primado toledano y Juan II realizaron juntos su entrada en Burgos tras salir de Navarrete, llevando el primero ante sí la cruz alzada como símbolo de su primacía, en presencia de numerosos testigos seglares y eclesiásticos. Esta entrada del primado toledano en Burgos quedó recogida en un testimonio notarial que fue solicitado por el arcediano de Sigüenza y canónigo toledano Pedro García de Huete, quien era mayordomo del arzobispo Carrillo, testimonio claramente parcial en el cual se da a entender que el obispo de Burgos no manifestó ninguna oposición a dicha entrada del primado toledano con la cruz alzada ante $\mathrm{si}^{30}$. No obstante, la realidad fue bien distinta, como muestran los acontecimientos que se sucedieron.

En efecto, el 3 de octubre Alonso de Cartagena lanzó una nueva sentencia de excomunión, dirigida en esta ocasión directamente contra el prelado toledano ${ }^{31}$. El día 20 del mismo mes la sentencia se leyó públicamente en el púlpito de la catedral burgalesa, el 24 se hizo en la iglesia de San Juan de Lerma y un día después en la iglesia de Santa María de Almansa de Castrojeriz ${ }^{32}$.

A su vez, Alonso Carrillo lanzó también una sentencia de excomunión contra el obispo y cabildo catedralicio de Burgos por oponerse a sus prerrogativas de primado, en virtud de las mencionadas bulas de Martín V en las que se reconocía al arzobispo de Toledo, como primado, "facultad e actoridat para traher e faser traher delante sí la crus levantada e enfiesta por todos los reynos de España" ${ }^{33}$. Además, el prelado toledano buscó imponer a toda costa y públicamente su autoridad en el litigio, y prueba de ello es que el cabildo catedralicio burgalés tuvo que dirigirse a Juan II pidiendo su protección y exponiendo cómo algún tiempo atrás, el Domingo 29 de septiembre, día de San Miguel, mientras se decía misa en la catedral de Burgos ante todos los fieles, irrumpieron en el templo el bachiller de Herrera y Martín de Ávila, y en nombre del arzobispo Alonso Carrillo:

...queriendo ofensar la libertad e ymunidat desta vuesta eglesia e çibdat e las personas dellas, non contentos de leer e publicar çiertas cartas que mostraron que trayan de excomunión e entredicho para esta dicha çibdat en el púlpito desta eglesia de Burgos, entraron dentro del coro e se posieron çerca del altar mayor, fueron requeridos que... çesasen por entonçe de leer las dichas cartas estando so çiertas apellaçiones interpuestas e non teniendo juridiçión ${ }^{34}$.

El intercambio de sanciones espirituales entre ambos prelados exigió la intervención del pontífice romano, Nicolás V, que el 29 de noviembre de ese mismo año ab-

${ }^{30}$ El testimonio notarial está datado en Burgos el mismo 12 de septiembre de 1448. Archivo Catedralicio de Toledo, X.8.B.1.3. Cit. Villarroel González, Ó., Las relaciones entre la monarquía y el arzobispado de Toledo..., p. 206.

${ }^{31}$ ACB, vol. 56, ff. 916r-918v.

${ }^{32}$ ACB, vol. 36, f. 134v.

${ }^{33}$ ACB, vol. 36, f. 69r. El 23 de agosto de 1448 Pedro Rodríguez de Grijera, canónigo y procurador del cabildo catedralicio burgalés, había pedido a Pedro Fernández Carrillo, procurador del arzobispo toledano, que le presentase las bulas de Martín V en las que se concedía el mencionado privilegio. Ibídem.

${ }^{34}$ ACB, vol. 56, f. 940v. 
solvió al obispo Alonso de Cartagena y a varias dignidades de la iglesia burgalesa de las censuras impuestas por el arzobispo de Toledo ${ }^{35}$. Poco antes, el 13 de noviembre, a petición del obispo de Burgos, el papa había admitido el litigio ante el tribunal de la Rota romana ${ }^{36}$. Las letras citatorias del pleito fueron presentadas el 17 de febrero de 1449 a Eugenio Alfonso de Solís, procurador de Alonso de Cartagena y del cabildo catedralicio burgalés ${ }^{37}$, y el 22 de mismo mes al arzobispo Alonso Carrillo, que en ese momento se encontraba con la Corte en Valdecuriel, diócesis de León ${ }^{38}$. Al año siguiente, el 23 de diciembre de 1450, el auditor apostólico declaró nulas las sentencias lanzadas por el arzobispo toledano contra el obispo y cabildo catedralicio de Burgos ${ }^{39}$.

El conflicto aún permanecía vigente en 1452, cuando Juan II medió entre los prelados litigantes para que llegasen por sí solos a un acuerdo ${ }^{40}$, que finalmente se produjo en el Real sobre Escalona, diócesis de Toledo, el 10 de junio de 1453, estando presentes Alonso Carrillo y Alonso de Cartagena, quienes ratificaron la avenencia con su firma y sellos ${ }^{41}$. En este acuerdo se relatan las diversas fases del largo pleito, que ambos obispos renuncian a continuar, estableciéndose que el arzobispo de Toledo, en su condición de "primado de Hispania" y no como metropolitano con potestad jurisdiccional sobre Burgos, pudiese llevar la cruz alzada en esta última ciudad y diócesis, incluso delante del propio obispo diocesano, y que pudiese asimismo bendecir al pueblo, celebrar vestido de pontifical y asistir a los oficios divinos con las ceremonias debidas al primado. El prelado toledano, como contrapartida, en su nombre y el de sus sucesores, hubo de reconocer a la diócesis burgalesa su condición de exenta respecto a cualquier metropolitano y dependiente directamente de la santa sede. Por último, se estableció solicitar al papa la ratificación del acuerdo, imponiéndose censuras a cada una de las partes que no lo respetasen ${ }^{42}$. Dos meses más tarde, el 25 de agosto, el cabildo catedralicio toledano ratificaría esta avenencia ${ }^{43}$.

${ }^{35}$ Dicha absolución pontificia se llevó a cabo por mediación de Antonio Pérez, auditor del tribunal de la Rota y canónigo segoviano. ACB, vol. 7, parte $1^{\text {a }}$, f. 226.

${ }^{36} \mathrm{ACB}$, vol. 36, f. 38v.

${ }^{37} \mathrm{ACB}$, vol. 36, f. 38v.

${ }^{38} \mathrm{ACB}$, vol. 36, f. 38v.

${ }^{39}$ ACB, vol. 36, f. 41r.

40 Serrano, L., Los conversos don Pablo de Santa María y don Alonso de Cartagena, Madrid, 1942, pp. 202-203.

${ }^{41}$ ACB, vol. 36, f. 50.

${ }^{42}$ El obispo de Burgos acepta que el prelado toledano, como primado, y sus sucesores "in signum excellencie et preminencie vostre dignitatis potestis et posint facere deferri libere crucem elevatam coram vobis et ipsis in civitate ac diocesis nostra burgensis", mientras que el arzobispo don Alonso Carrillo reconoce que el prelado burgalés y sus sucesores son "speciales Sancte Sedi apostolice suffraganeos et illi inmediate subiectos". ACB, vol. 36, f. 50. Para demostrar la exención de que gozaba la diócesis burgalesa, el obispo Alonso de Cartagena y el cabildo catedralicio habían solicitado a la Santa Sede un testimonio de la misma, que fue otorgado en Roma el 4 de julio de 1452. En este testimonio, dado por Luis, cardenal de San Lorenzo en Dámaso, de la Cámara Apostólica, se confirma cómo en el llamado Libro Censal, del año 1192, en el que se recogen todas las diócesis exentas de la cristiandad latina, también figura como exenta y sujeta directamente a la Santa Sede la diócesis de Burgos, en el reino de Castilla. ACB, vol. 36, f. 132r.

${ }^{43}$ ACB, vol. 36, f. 51. 
A la hora de valorar el contenido de este acuerdo debe destacarse el hecho de que, aunque se tienen en cuenta los intereses de ambas partes, el arzobispo de Toledo parece salir mucho más beneficiado al permitírsele finalmente portar la cruz alzada, razón fundamental de toda la discordia, incluso delante del propio prelado burgalés, con todo lo que ello implicaba de patente ostentación simbólica de la supremacía jerárquica del primado toledano, aun cuando este último reconociese a su vez la exención de que gozaba la diócesis de Burgos y su directa dependencia de la santa sede. Además, si jurídicamente la exención de una diócesis determinaba su sometimiento exclusivo al papado, no deja de resultar extraño que en el acuerdo se establezca que el prelado toledano pueda portar la cruz alzada por todo el obispado de Burgos en calidad de primado, pues dicha exención también debía serlo respecto al primado.

Por otro lado, hay que poner de relieve la previa mediación regia en el conflicto antes de que se llegase a un acuerdo definitivo para la resolución del mismo, acuerdo en cuyos contenidos se podría ver también la influencia del monarca, claramente interesado en salvaguardar la primacía del prelado toledano, y ello a pesar de que Alonso de Cartagena era también un estrecho colaborador regio. Se trata, pues, de una intervención del monarca en un problema aparentemente de índole puramente religiosa pero que tenía un cierto trasfondo político si se tiene en cuenta el poder de que gozaban los arzobispos toledanos y el importante apoyo político y religioso que en momentos cruciales podían prestar a la monarquía. De hecho, en siglos anteriores también está documentado el interés que la monarquía castellana siempre demostró por mantener y defender la primacía toledana frente a los recelos de otros prelados del reino ${ }^{44}$.

En el origen del largo conflicto que se planteó hay que destacar también la propia indefinición que en los privilegios pontificios se daba respecto a la jurisdicción del primado, lo que contribuyó a originar este tipo de pleitos, que también se produjeron durante esas décadas en otras diócesis hispanas, cuyos prelados se rebelaron contra la ostentación en su obispado del título de primado por parte de los arzobispos de Toledo ${ }^{45}$.

Quizá en todo el conflicto recién analizado pueda verse también la transposición eclesiástica de la secular rivalidad entre las ciudades de Burgos y Toledo, cuyos procuradores se disputaban la prelación en las reuniones de Cortes, a la vez que también cabe percibir ecos de este enfrentamiento en el prólogo de la Anacephaleosis, la principal obra histórica de Alonso de Cartagena, en concreto en la justificación de la dedicatoria de la obra al cabildo catedralicio burgalés, donde se denomina a la

${ }^{44}$ Villarroel González, Ó., Las relaciones entre la monarquía y el arzobispado de Toledo..., p. 207. En el siglo XIII Alfonso X y Sancho IV, por ejemplo, intervinieron en los enfrentamientos acaecidos entre los arzobispos de Sevilla y Toledo, tomando una actitud favorable al mantenimiento de la primacía toledana, que los prelados hispalenses se negaban a aceptar. NiETo Soria, J. M., Iglesia y poder real en Castilla. El episcopado, 1250-1350, Madrid, 1988, pp. 217-220.

45 Por ejemplo, la entrada en 1431 del arzobispo de Toledo Juan Martínez Contreras en el reino de Aragón con la cruz alzada se encontró con la resistencia del obispo de Tarazona, Jorge de Bardaxi, quien defendió la superioridad del arzobispo de Zaragoza, originándose un pleito que se dilató por dos años en la curia romana hasta que en 1433 Eugenio IV ordenó su suspensión. ViLlarroel GonzÁlez, Ó., Las relaciones entre la monarquía y el arzobispado de Toledo..., p. 204. 
sede de Burgos como "cabeza de Castilla", integrándose así orgullo eclesiástico y sentimiento cívico ${ }^{46}$. No hay que olvidar, por otro lado, el papel que en el desarrollo de este conflicto pudo jugar la propia experiencia personal que Alonso de Cartagena había acumulado durante su larga trayectoria política en lo concerniente a la defensa de determinados privilegios, tal como había hecho años atrás, en septiembre de 1435, en el concilio de Basilea al defender sobre la base de argumentos históricos la preeminencia de la embajada castellana frente a la inglesa respecto a los asientos a ocupar en el concilio ${ }^{47}$. No en vano incluso Eneas Silvio Piccolomini llegaría a elogiar las grandes dotes intelectuales y la extraordinaria capacidad oratoria del prelado burgalés ${ }^{48}$.

Ya para concluir no queda sino señalar que, a pesar del acuerdo al que tras el largo pleito se llegó en 1453, en momentos posteriores, ya en pleno siglo XVI, todavía volverían a producirse en ocasiones nuevos conflictos puntuales de similares características, aunque desde luego no tan intensos como el recién analizado. Una prueba de ello viene dada por el poder que el 10 de agosto de 1558 otorgó el obispo de Burgos Francisco de Mendoza a su hermano, el arcediano de Toledo Fernando de Mendoza, para que en su nombre, por depender la diócesis de Burgos directamente de la santa sede, pidiese al entonces arzobispo toledano, Bartolomé de Carranza, que no llevase ante sí la cruz alzada mientras pasaba por el obispado burgalés, cosa que de hecho el toledano ya había comenzado a hacer. En esta ocasión parece que el primado toledano procedió de inmediato a hacer lo que se le pedía, guardando en una caja la cruz de plata que llevaba alzada ante $\mathrm{sí}^{49}$. Con todo, ello constituye una muestra de la pervivencia multisecular del extraordinario valor que en los procesos de relación de poder, dentro del propio estamento eclesiástico, se otorgaba conscientemente a todos los elementos simbólicos, a los que se dotaba de una amplia dimensión representativa, siendo la cruz alzada un claro exponente a este respecto.

\section{APÉNDICE DOCUMENTAL}

Burgos, 23 de agosto de 1448 .

Alegaciones y apelación presentadas por Pedro Rodríguez de Grijera, bachiller en Decretos, como procurador del obispo de Bur gos Alonso de Cartagena, en el pleito entre este último y el arzobispo de $T$ oledo, Alonso Carrillo, defendiendo el carácter exento de la diócesis burgalesa y su directa dependencia de la Santa Sede,

${ }^{46}$ Fernández Gallardo, L., Alonso de Cartagena. Una biografía politica en la Castilla del siglo $X V$, Valladolid, 2002, p. 270.

${ }^{47}$ Sobre los elementos retóricos del discurso De preeminentia que Alonso de Cartagena pronunció en Basilea en defensa de la embajada castellana puede verse Fernández Gallardo, L., Alonso de Cartagena..., pp. 142-158. Asimismo, un detallado estudio sobre el importante papel desempeñado por Alonso de Cartagena durante el desarrollo del conflicto anglo-castellano en Basilea aparece recogido en el trabajo del mismo autor "Alonso de Cartagena en Basilea (nuevas observaciones sobre el conflicto anglo-castellano)", Archivos Leoneses, 95/96 (1994), pp. 9-91.

${ }^{48}$ Fernández Gallardo, L., Alonso de Cartagena. Una biografía política..., p. 158.

${ }^{49}$ ACB, vol. 56, f. 928r-929r. 
y en contra de la pretensión que el prelado toledano tenía de, en razón de su primacía, hacer uso de los especiales honor es y prerrogativas de primado en la ciudad y obispado de Burgos.

$$
\text { ACB, vol. 36, ff. 58r-62r. }
$$

In domini nomine, amen. Sepan quantos este público instrumento vieren commo en la muy noble çibdat de Burgos, a veynte e tres días del mes de agosto, año del nasçimiento del nuestro señor Ihesu Christo de myll e quatroçientos e quarenta e ocho años, en presençia de nos los notarios públicos e testigos ynfraescriptos, este día, estando presente el honrado Martín de Ávila, notario apostólico, paresçió y presente Pero Rodrígues de Grijera, bachiller en Decretos, benefiçiado en la eglesia de Burgos, procurador que se mostró ser del muy reverendo in Christo padre e señor don Alfonso, por la graçia de Dios e de la santa eglesia de Roma obispo de Burgos, espeçial sufragáneo de la sede apostólica e a ella inmediatamente subgecto, e oydor de la audiençia de nuestro señor el rey, e su referendario e del su consejo, de la qual procuraçión fasemos fee nos los dichos notarios, e mostró e presentó ante el dicho Martín de Ávila un escripto de rasones e un escripto de allegaçiones de nullidat e apellaçión, el thenor de lo qual todo es este que se sigue.

Discrecto varón Martín de Ávila. Yo el bachiller Pero Rodrígues de Grijera, benefiçiado en la eglesia de Burgos, procurador que so del reverendo in Christo padre e señor don Alfonso, por la graçia de Dios e de la santa eglesia de Roma obispo de Burgos, espeçial sufragáneo de la santa see apostólica e a ella inmediatamente subjecto, e oydor de la audiençia de nuestro señor el rey e su referendario e del su consejo, vos digo que bien sabedes commo por vos, asy commo por notario apostólico, fue mostrada una escriptura al dicho señor obispo, que desíades ser proçeso fecho por don Pedro, de buena memoria, obispo que fue electense, commo executor que se dixo de çiertas letras apostólicas que dixo aver emanado del papa Martino quinto, de bienaventurada memoria, en fabor de los arçobispos que por tiempo fueron de Toledo, para que por rasón de çierta primaçía les sea fecho honor en los asentamientos e en otras cosas e puedan gosar de çiertas insignias e otras prerrogativas, segund que más largamente en las dichas letras se dise ser contenido. E por quanto por vos non es mostrado a cuya pectiçión nin a qué fin la dicha escriptura mostrastes, vos pido e requiero que sy algund pedimiento o requerimiento vos fue o fuere fecho por parte de alguno, que me dedes copia del para que yo responda en el dicho nombre. E demás desto digo que la intençión del dicho señor obispo nunca fue nin es de contradesir a cosa tocante a honor e veneraçión de la persona del señor arçobispo que agora es nin de los otros arçobispos que por tiempo fueren en Toledo, salva la libertad del dicho señor obispo e de su silla obispal e de su eglesia e diócesis e de la ynmediata subjeçión que la santa see apostólica sobre él e sobre su dignidat tiene. E sy por ventura en la dicha escriptura que dixistes ser proçeso algo contra esto se contiene, dígolo todo ser ninguno, o a lo menos mucho agraviado, por las causas e rasones por mí en el dicho nombre dichas e allegadas contra una carta dada por don Pero Ferrándes Carrillo, prior de la eglesia de Córdova, asy commo subexecutor que se dixo del dicho proçeso, [...] que he aquí por repetidas. E pido a los notarios infraescriptos que las puxieran / de verbo ad verbum, las quales allego e he por allegadas en quanto se pueden adaptar e adaptan contra lo dicho fecho e proçedido por el dicho don Pedro, obispo electense. E sy e en cuanto alguno mucho agraviado por ende apelló de todo ello para ante la see apostólica, ante la qual so presto de seguir las causas de la dicha nullidat e agravios, e pido los capítulos sy ay alguno que me los 
pueda dar una, dos e tres veses, instante [...] instantisime, con aquella instançia e deligençia que devo e pongo al dicho señor obispo, e a my en su nombre, e a todos sus bienes espirituales e temporales, privilleios, inmunidades e libertades so amparo e proteçión de la santa see apostólica, cuyo espeçial e inmediatamente subjecto, segund dixe, es. E pido e requiero a vos el dicho Martín de Ávila, commo a persona pública, que lo notifiquedes e fagades saber a qualquier persona que sobre ello vos requirió o requiriere, e pido a los presentes notarios o a qualquiera dellos que me lo den por testimonio, signado con su signo, e a los presentes ruego que sean dello testigos.

Honrado varón don Pero Ferrándes Carrillo, prior de la eglesia cathedral de Córdova, jues subexecutor que vos desides tomado e excogido en el negoçio ynfraescripto por parte del muy reverendo in Christo padre e señor don Alfonso Carrillo, por la myseraçión divina arçobispo de Toledo, por virtud de dos bullas que desides aver emanado del muy santo padre el papa Martino quinto, de bienaventurada recordaçión, una graçiosas e otra executoria, e por virtud de un proçeso que desides ser fecho sobre las dichas bullas por el reverendo in Christo padre e señor don Pedro, de buena memoria, obispo electense, jues executor que desides que fue prinçipal con otros sus collegas en el dicho negoçio, espeçialmente por la dicha bulla executoria, sobre rasón de la dignidat arçobispal e primaçial de la eglesia e arçobispado de Toledo, e honores e preheminençias e insignias a ella devidas, deputado que vos desides por virtud de la cláusula çeterum en el dicho proçeso contenida. Yo Pero Rodrígues de Grijera, bachiller en Decretos, benefiçiado en la eglesia de Burgos, procurador que so del reverendo in Christo padre e señor don Alfonso, por la graçia de Dios e de la santa eglesia de Roma obispo de Burgos, espeçial sufragáneo de la santa see apostólica e a ella inmediatamente subjecto, e oydor de la audiençia de nuestro señor el rey e su referendario e del su consejo, e de los honorables señores deán e cabillo de la dicha eglesia de Burgos, e de don Juan Ruys, arçediano de Burgos, [entre líneas: e de don Luys Gonçáles de Llanos, capiscol], e de don Juan de Velasco, arçediano de Valpuesta, e de don Sancho de Prestines, arçediano de Palençuela, e de don Pero Martínes de Ayllón, abad de Fonçea, en su nombre protestando de non vos aver por jues mas por privada persona, segund que adelante diré, e de non consentir en cosa alguna por vos fecha nin vos dar nin atribuyr iurisdiçión por acto alguno o cosa que diga o faga, digo que una carta que suena ser dada por vos fue leyda a los dichos mys partes / o algunos dellos, la qual en efecto contiene que por parte del dicho señor arçobispo vos fue denunçiado commo él, tenyendo de derecho e por las dichas bullas apostólicas e proçeso sobre ellas fecho averle seydo dada facultad e actoridat para traher e faser traher delante sy la crus levantada e enfiesta por todos los reynos de España, e que por las dichas mis partes fue opuesto para ge lo perturbar e impedir la dicha su autoridat arçobispal e primaçial que de derecho e por virtud de las dichas bullas e proçeso dise que tiene, fasiendo sobre ellos algunos actos e mandado el dicho señor obispo guardar entredicho, por lo qual fasedes çiertos mandamientos so çiertas coniuraçiones, segund que en la dicha vuestra carta más largamente se paresçe contener. Lo qual todo avido por repetido, digo que lo contenido en la dicha vuestra carta es ninguno e de ningund valor, por muchas manyfiestas iurídicas rasones que del thenor de la dicha vuestra carta paresçen e se pueden collegir, e por otras que al propósito fasen e he por dichas e allegadas, e señaladamente por las seguientes.

La primera porque todo aquel aquel que, commo jues delegado o subdelegado de la santa see apostólica, quiere proçeder deve mostrar escriptura sufeçiente por donde paresça el poderío a él otorgado, e vos non avedes mostrado nin mostrades bulla original por donde 
conste e se prueve fundamento alguno donde vos pueda nasçer nyn nasca poderío alguno nyn iurisdiçión. Por ende sodes de aver por persona mera privada fasta que la tal bulla mostredes, la qual vos pido e requiero sy alguna tenedes que me la mostredes en presençia de notario e testigos, e me desdes luego copia della que se collaçione e se conçierte con el original, porque aquélla vista se paresca que es lo que por virtud della se puede disponer, e las dichas mis partes fagan sobre ello lo que devieren con derecho, a lo qual son prestos e se ofresçen de faser. La segunda por quanto, aunque alguna bulla apostólica emanase, lo que non paresçe, vos non podríades nin sedes subexecutor, por quanto segund que en vuestra letra se contiene el proçeso que desides que emanó sería fecho por don Pedro, de buena memoria, obispo que fue electense, el qual fue e es finado e pasado desta vida temporal antes del tiempo que vos desides aver seydo elegido por subexecutor, e asy las comysiones so la cláusula çeterum avrían expirado por su fin, e non podría por virtud della subexecutor alguno ser tomado, e sy se tomase non avría iurisdiçión alguna, ca caso que el poder de los executores prinçipales de las graçias fechas por el papa se diga duran después del finamiento del papa que otorgó las graçias, pero esto es espeçial en ellos por la dilaçión que se seguiría de recorrir al papa, mas non se falla esto expreso en los subexecutores nin en otros jueses delegados o subdelegados, e asy en ellos es destar a la regla del derecho común, que dispone por la muerte del delegante expira la comysión, de lo qual se sigue vos ser mera privada persona, e non tener iurisdiçión alguna. Por ende yo vos requiero en el dicho nombre que non proçedades commo jues nin vos llamedes jues nin subexecutor, pues non lo sedes, nin usedes de iurisdiçión alguna. Por ende / yo vos requiero en el dicho nombre que non proçedades commo jues nin vos llamedes jues nin subexecutor, pues non lo sedes [sic], nin usedes de iurisdiçión pues non la tenedes. En otra manera, protesto que incurrades en aquellas penas en que incurren los que usan de iurisdiçión non la tenyendo, e podades por esta causa ser coherçido e punido commo exçedente e cometiente exçeso e cosa non devyda en esta çibdat e dióçesis. La terçera, por quanto vos sedes familiar continuo comensal del dicho señor arçobispo, degesee que non podríades ser tomado con derecho por jues nin subexecutor en la tal causa. La quarta, por quanto por parte del dicho señor arçobispo fue intimada al dicho señor obispo una apellaçión o provocaçión que dixo avía fecha en este negoçio, asignando çierto término a que las partes paresçiesen en corte romana, a la qual el dicho señor obispo respondió en çierta forma. E aun después desto, por parte del dicho señor arçobispo fue interpuesta otra apellaçión en este mesmo negoçio para delante la santa see apostólica, e el dicho señor obispo asignó çierto término para responder a ella, el qual non es aún allegado, e entiende responder a ella commo deviere con derecho, segund que todo pasó por Martín de Ávila, su secretario. Por ende, pues por parte del dicho señor arçobispo fueron interpuestas apellaçiones o provocaçiones en este mesmo negoçio, e por vigor dellas quanto en él fue quiso debolver e debolvió e fue debuelto a la dicha santa see apostólica e a la su corte romana, non podría él començar otro letijo nin ynovar cosa alguna en perjuysio de aquella pendençia que por su parte fue fecha, nin alguno aunque alegara jurisdiçión toviese non se podría en ello entremeter, salvo el dicho señor papa o aquel a quien su santidat lo cometiese. La quinta porque, aunque una copia que non fase fee, por virtud de la qual dis que vos pretendedes ser fecho el proçeso, paresçiese originalmente en manera que fisiese fee, lo que non paresçe, e vos fuesedes subexecutor, lo que non sedes, lo contenido en vuestra letra, todo o en muchas de sus partes, sería e es ninguno por quanto exçederíades commo exçededes los términos en la dicha pretensa bulla, e aún en el proçeso que sobre ella se dise ser fecho, avenidos, ca vos entremetedes en la dicha vuestra 
carta a fablar en lo conçerniente a la dignidat arçobispal e en otras cosas de que non fase mençión en la dicha allegada bulla. La sexta, por quanto la disposiçión o declaraçión que en la dicha bulla se dise ser contenida non se extiende a lo por vos dicho e proçedido, ca las disposiçiones de los derechos e de los derechos e de los rescriptos de los romanos pontífices e prínçipes, cuando contiene alguna clásula general, hase de entender en las cosas que son de la qualidat de lo primeramente espeçificado e non en las otras de género e qualidat, nin en las que son más graves e de mayor importançia. E commo en la dicha allegada bulla en la primera cláusula se fabla expresamente en las cosas tocantes a la reverençia e honor de la persona, que consisten en el preçeder en el asentamiento e en otras veneraçiones honrosas, conseguiente cosa es que la cláusula postrímera que fabla generalmente de las otras prerrogativas, previlleios e insignias se entienda de las que son de aquella qualidat, es a saber, de lo tocante a honor e veneraçión de la persona, e non de las cosas tocantes a otros actos. E la intençión de mis partes non es nin fue de embargar cosa que toque a honor de la persona del dicho señor arçobispo nin orden de su asentamiento nin a otras veneraçiones nin honores personales, antes les plaserá e plase de qualquier honor que sea dado a los arçobispos que por tiempo fueren de Toledo que non sea en perjuysio de la silla obispal de Burgos nin de los obispos que por tiempo en ella fueren. La séptima, puesto que alguno quisiese poner dubda en commo se deven entender las dichas palabras, la declaraçión dellas pertenesçía e pertenesçe a nuestro señor el papa e a su santa see apostólica, de quien se dise aver emanado, ca a aquel pertenesçe la interpetraçión e declaraçión a quien pertenesçe poderlo otorgar e disponer de nuevo. E el executor de las tales letras, e mucho menos el subexecutor, non podría declarar las tales palabras nin traherlas a espeçificaçión a su voluntad, mas deve adherir a la forma espresada en las letras apostólicas e non sallir della en cosa alguna, e sy sale o exçede lo contenido en las tales letras es avido por fecho por persona mero privada, e lo por él dicho o proçedido es ninguno e de ningund valor, segund que fue e es lo por vos fecho. Ca porque todo omme vea más manyfiestamente la nulidat de lo contenydo en vuestra letra, es de considerar que una es la dignidat arçobispal e otra la primaçial, ca muchos arçobispos ay que non son primados, e a los que lo son algunas cosas les compete commo a arçobispos, e otras commo a primados, e diversos son los fines e términos de las dichas dignidades. E en lo que toca a la dignidat arçobispal de Toledo non fabla la dicha pretensa bulla, por ende en esto bien veedes que non avedes color alguno para fablar, e en quanto es a lo prinçipal la dicha pretensa bulla fabla generalmente desiendo insignias et çetera, e quales son éstas non lo declara, por ende non es vuestro de declarar nin terníades vos en ello que faser, aunque fuésedes executor, lo que non sedes, ca hase de declarar por jues competente, e el executor nin el subexecutor non deve sallir de las palabras de las letras apostólicas, e asy lo suelen guardar los executores que justamente quieren exerçer su ofiçio, por quanto todo lo que alliende fisiesen sería / ninguno commo fecho por personas privadas, segund que es lo por vos proçedido. La octava, porque segund que por la dicha copia paresçe, las palabras della son generales e non tocantes a lo que queredes mandar por vuestra letra, segund que más largamente se dirá e mostrará sy e donde deviere. La nona, porque aunque dello disposiesen serían ygualar los primados de las Españas so palabras generales con los otros patriarchas e primados, los quales, exçeptos los quatro patriarchas prinçipales, de quien en la dicha allegada bulla non se fase mençión, çierto es que non pueden faser lo que vos queredes mandar fuera de los límites de su primaçía. E pues la dióçesis de Burgos non es inclusa so términos de primaçía nin patriarcado, salvo solamente so el pontificado romano a quien los obispos de Burgos son inmeditamente subjectos e cuyos 
son espeçiales sufragáneos, caso que el dicho señor arçobispo sea primado e deva gosar de las insignias de los otros primados, esto sería en otras partes donde se extendiese su primaçía, mas no en esta diócesis, la qual non es dentro de fines de algund patriarcado nin primaçía, mas sola e inmediatamente so el pontificado romano, nin a esto embarga que digan que sea llamado primado de las Españas, ca nin por eso non se sigue que todas las partes de España sean so su primaçía, ca manifiesta cosa es, asy en derecho commo por experiençia e enxiemplo de otras regiones, que las intitulaçiones generales de las tierras non fasen prueva en cada parte dellas. Por ende, aunque él sea primado de las Españas, non se sigue que todas las partes de España sean so aquella primaçía, e muéstrase esto bien por expiriençia en otras dignidades asy eclegiásticas commo seglares por densas partes del mundo, ca el rey don Alfonso, aquel que ganó a Toledo, que fue en fundar la silla obispal en este obispado e la doctó primeramente, segund por sus escripturas paresçe intitula a la silla obispal desta çibdat por cabeça de la diócesis de toda Castilla, queriendo aver al obispo de Burgos por obispo de toda Castilla, mas non se sigue por eso que toda Castilla es en la diócesis de Burgos, mas porque se pone nombre general a las veses por respecto a la parte más prinçipal, e commo entonçe eran más angostos los términos del reyno llamó a la diócesis de Burgos de toda Castilla. E el arçobispo lugdonense, que es en Françia, primado de las Galias se llama, mas manifiesta cosa es que muchas dióçesis ay en ambas las Galias, asy çisalpina commo transalpina, que non son so su primaçía. E en las dignidades seglares asaz enxemplos / ay notorios a todos los que en ellos quesieren considerar, que muchos duques ay por diversas partes que se intitulan de algunas provinçias, mas non son todas ellas so sus ducados, mas fásense aquellas intitulaçiones por tener alguna parte en ellas, aunque no todo. E asy la dicha intitulaçión non fase prueva alguna para en esta dióçesis, cuyo perlado es libre e subgecto inmediatamente al suberano perlado que es el papa, e su espeçial sufragáneo. La désima, por quanto la silla obispal de Burgos e los obispos que por tiempo en ella fueron siempre fueron libres e inmediadamente subjectos a la santa see apostólica, e non situados so provinçia alguna, e asy da dello testimonio el papa mismo que autorisó la fundaçión desta silla obispal, ca testifican de no ser so metropoli alguna, la resçibió para sy en propio derecho de la see apostólica, e a los obispos en sus espeçiales sufragáneos, segund se mostrará sy e en donde e quando cumpliere. Por ende la dicha bulla non se extendería en perjuysio desta silla e de los obispos della, nin sería tal la intinçión del papa, ca la conçesión de los padres santos e de los prínçipes entiendese syn perjuisio de derecho ageno. La undéçima, por quanto los obispos que por tiempo fueron e el dicho señor obispo e la dicha silla obispal estovieron e están en posesión vel quasy paçífica de la dicha íntegra libertad e ingunidat e inmediata subjeçión a la see apostólica de tanto tiempo acá que memoria de omes non es en contrario, sabiéndolo los arçobispos de Toledo que por tiempo fueron, e consentiendo algunos dellos espresamente quando en ello se fablava, e los otros táçitamente syn reclamar nin desir cosa contra ello, lo qual es notorio e asy lo afirmo ser notorio en esta çibdat e en todo su obispado, e en la corte de nuestro señor el rey, que es lugar público general e común a todos los del reyno, e en todas las partes del reyno, e aun en la corte romana, segund se mostrará sy e quando cumpliere. Por ende, caso que la dicha pretensa declaraçión, segund sus palabras, incluyese el caso, lo que non incluye, sería claramente subretiçia e nulla quanto a esto atañe por non faser mençión de la quasy posesión paçífica en que la dicha silla obispal e el dicho señor obispo e los otros obispos sus predeçesores fueron e son, e asy por virtud della non se pararía perjuysio alguno a las dichas mis partes. La duodéçima, por quanto en la dicha vuestra carta non se contiene audiençia alguna, nin por 
ella paresçe darse lugar a que mys partes dixiesen de su derecho, e asy lo en ella contenydo, commo aquello que proçedió syn ser oyda nin llamada la parte e contra toda orden de derecho, e conteniente error expreso de derecho, es ninguno e de ningund valor.

Por las quales rasones e cada una dellas que he por dichas e allegadas en su devida orden/, cada una dellas sin perjuysio de las otras, e por todas las otras que a este proçeso se pueden traher, las quales he por espresadas, digo todo lo contenido en la dicha vuestra carta e cada cosa dello ser ninguno e de ningund valor, commo aquello que es fecho syn iurisdiçión e contiene error expreso de derecho, e caso que ello o parte dello fuese alguno sería muy agraviado. Por ende apello de vos e de todo lo por vos mandado, dicho e fecho en la mejor forma e manera que puedo e devo de derecho ante nuestro señor el papa, Nicolao quinto, e la santa see apostólica, e pongo a las dichas mis partes e a cada una dellas, e a my en su nombre, e a sus bienes espirituales e temporales e derechos e iurisdiçiones e todo lo a ello tocante so defensión e amparo del dicho señor papa e de la santa see apostólica, e pido los capítulos una e dos e tres veses, instante instantiam instantisime, con aquella deligençia e instançia que devo e es complidero para el oferto del presente acto. E pido a los presentes notarios que están presentes e a qualquier dellos que lo de asy signado, e a los presentes que sean dello testigos para guarda del derecho de las dichas mys partes e a my en su nombre. Otrosy, vos notifico en el dicho nombre a vos e a los que lo quisiesen saber que el dicho señor obispo alçó e relaxó puramente el entredicho que en esta çibdat estava por causas rasones que a ello le movieron. Segund que pasó por Pero Rodrígues, notario, e es presto de faser todas e qualesquier cosas que por mandamiento le sean jurados, en quanto deva e a él pertenesca de faser.

El qual dicho escripto presentado, e asymesmo notificada la dicha apellaçión, el dicho Martín de Ávila dixo que non sabía a qué desía, pero que pedía traslado. Testigos Gómes Ferrándes, secretario del dicho señor arçobispo, e Iohan de Alcalá, e Diego de Bahena, familiares de don Pero Ferrándes Carrillo, prior de Córdova, e don Sancho de Prestines, liçençiado en leyes, arçediano de Palençuela, e Nuño de Salasar e Alfonso de Truxillo, sus escuderos, e el bachiller Alfonso Martínes de Villahos.

Yo, Alfonso Sánches de Marquina, clérigo de Burgos, notario público por la abtoridat apostólica, que a todo lo que susodicho es en uno con el dicho Pero Rodrígues de Velsorado, notario, e con los dichos testigos presente fui, e a pedimiento e requerimiento del dicho Pero Rodrígues de Grijera, bachiller, este público instrumento fise escrevir, el qual va escripto en quatro fojas de paper de dos de pliego, en esta aquí va este my signo, e por ende fis aquí este mío signo a tal en testimonio de verdat. Alfonso Sánches de Marquina. / Va escripto entre renglones en la segunda plana do dise e de don Luys Gonçáles de Llanos, capiscol, non empesca.

Yo, Pero Rodrígues de Velsorado, escrivano e notario público por las actoridades apostolical e real, que a todo lo susodicho e a cada cosa dello fuy presente en uno con el dicho Alfonso Sánches de Marquina, notario, e con los dichos testigos, e a pedimiento del dicho bachiller Pero Rodrígues, en el dicho nombre del dicho señor obispo, este instrumento escreví en esta pública forma, en el qual en esta otra foja signó su signo el dicho Alfonso Sánches de Marquina, el qual va escripto en quatro fojas de papel, e más esta plana en que va este mío signo, e en fin de cada plana va señalado de my señal e de la señal del dicho Alfonso Sánches, notario. E por ende fis aquí este mío signo a tal en testimonio de verdat [firma notarial: Pero Rodrígues, notario]. 